\title{
Loud P2 on Cardiac Auscultation: A Useful Clinical Clue to Fluid Overload
}

\author{
Kamel El-Reshaid ${ }^{1, *}$, Shaikha Al-Bader ${ }^{2}$ and Raja Dashti ${ }^{3}$ \\ ${ }^{1}$ Department of Medicine, Faculty of Medicine, Kuwait University, Kuwait \\ ${ }^{2}$ Department of Medicine, Nephrology Unit, Al-Amiri Hospital, Kuwait \\ ${ }^{3}$ Department of Medicine, Cardiology Unit, Al-Amiri Hospital, Kuwait
}

*Corresponding author: Kamel El-Reshaid, Professor, Department of Medicine, Faculty of Medicine, Kuwait University, PO Box 24923,13110 Safat, Kuwait, E-mail: kamel@hsc.edu.kw

Received: 08 May, 2021 | Accepted: 02 Jun, 2021 | Published: 09 Jun, 2021

Citation: El-Reshaid K, Al-Bader S, Dashti R (2021) Loud P2 on Cardiac Auscultation: A Useful Clinical Clue to Fluid Overload. Int J Nephrol Kidney Fail 7(2): dx.doi.org/10.16966/2380-5498.210

Copyright: (c) 2021 El-Reshaid K, et al. This is an open-access article distributed under the terms of the Creative Commons Attribution License, which permits unrestricted use, distribution, and reproduction in any medium, provided the original author and source are credited.

\begin{abstract}
Patients with renal disease are at risk of fluid overload which escalates as the disease progresses. In the present study, we evaluated the increase in the intensity of the second heart sound generated by its pulmonary component (P2) and its correlation with fluid overload in such patients. To confirm its potentials and avoid interference with patients with cardiac disease; we included only those who lacked echocardiographic evidence of (a) ASD or VSD, (b) primary cardiac defects associated with high P2 viz pulmonary aneurysm, mitral stenosis and myocardial disease, (c) primary cardiac defects associated with soft P2 viz pulmonary stenosis, pulmonary atresia and tetralogy of Fallot, (d) primary cardiac defects associated with low A2 viz mitral regurgitation, aortic regurgitation, low diastolic arterial pressure, severe immobile aortic valve disease. To assess the extent of fluid overload; the clinical examination was complemented with radiological imaging as well as the echocardiographic measurement of systolic pulmonary arterial pressure. There was a significant correlation between P2 intensity and fluid changes. In conclusion; load P2 is a useful clinical clue to fluid overload and decline in its intensity correlates with the extent of fluid removal.
\end{abstract}

Keywords: Echocardiography; Fluid overload; P2; Renal disease

\section{Introduction}

In critically ill patients; positive fluid balance is associated with increased morbidity and mortality [1]. Salt and water retention inherent in acute kidney injury and/or chronic kidney disease; renders such patients at high risk for such complications independent of coincident sepsis and cardiac disease [2]. Fluid overload is defined by a cut-off value of $10 \%$ fluid accumulation above baseline body weight [3]. In critically ill patients; assessment of volume status remains difficult. Physical examination and portable chest $\mathrm{x}$-ray may prove to be difficult due to primary lung disease, chest infection, or morbid obesity [4]. Direct central venous pressure measurement requires critical unit admission and echocardiography as well as bioelectrical impedance analysis through rapid and non-invasive measures yet are expensive, operator-dependent and are not for day-care facilities $[5,6]$. Recently, BNP has been advocated to assist in such a field with its portable devices yet its expense and misleading higher values in acute cardiac insults, as well as its retention with renal disease, limits its application in this setting [7]. Patients with fluid overload have an increase in right ventricular pressure leading to an increase in pulmonary arterial pressure and accentuation of pulmonary component of second heart sounds (P2) [8-10]. Hence, and in an attempt to provide a simple, inexpensive and bed-side measurement of fluid overload; we conducted our study to evaluate the role of the intensity of $\mathrm{P} 2$ in this context.

\section{Patients and Methods}

The study was conducted between 1 January 2018 and 31 December 2020 to evaluate the correlation of loud P2 with fluid overload status in patients with chronic renal disease. Grading of the intensity of P2 was assessed at inclusion and after the establishment of euovolumic state.

\section{Selection criteria}

Patients with acute and/or chronic renal disease who presented with fluid overload.

\section{Exclusion criteria}

Morbidly obese patients, those with emphysema and those with echocardiographic evidence of:

a) ASD or VSD.

b) Primary cardiac defects associated with high P2 viz pulmonary aneurysm, mitral stenosis and myocardial disease.

c) Primary cardiac defects associated with soft P2 viz pulmonary stenosis, pulmonary atresia and tetralogy of Fallot.

d) Primary cardiac defects associated with low A2 viz mitral regurgitation, aortic regurgitation, low diastolic arterial pressure, severe immobile aortic valve disease. 


\section{Criteria for diagnosis of fluid overload}

The latter was established based on sacral and lower limbs oedema as well as bilateral basal rales on chest auscultation which was confirmed by chest $\mathrm{x}$-ray and CT.

\section{Measures of treatment of fluid overload}

It included intravenous and/or oral Furosemide+Spironolactone and/or thiazides.

\section{Grading of accentuation of P2}

It was done by comparing the auscultatory intensity of the second heart sound at the pulmonary area (P2) with that at the aortic area (A2). Grading was defined as (a) Mild or grade 1: when the intensity of P2 is equal to A2, (b) Moderate or grade 2: when the intensity of P2 exceeds A2, and (c) Severe or grade 3: when P2 is loud and banging and is audible beyond the pulmonary area [8]. Grading of the intensity of P2 was done by either of the 2 experienced consultant internists (first and second authors) and was blinded from the cardiologist at the time of echocardiography (third author).

\section{Echocardiographic assessment of the fluid status}

Grading was done using Doppler 2D echocardiography to measure systolic pulmonary arterial pressure (sPAP). Normal when $<30$, mild: 30-49, moderate: 50-75 and severe: $>75 \mathrm{~mm} \mathrm{Hg}$ [7].

\section{Statistical analysis}

SPSS statistical package version 25 was used for data entry and processing. The p-value $<0.05$ was used as the cut-off level for significance. Since the age, sPAP before and after fluid removal was normally distributed; the mean $\pm \mathrm{SD}$ was used to express them. Wilcoxon Signed Rank test was to compare P2 and sPAP before and after fluid removal. The correlation between $\mathrm{P} 2$ and sPAP values was tested using Spearman Correlation Coefficient.

\section{Results}

A total of 88 patients were selected for the study yet 8 were excluded for an associated cardiac disease. Four had mitral valve defects, 2 had aortic ones and 2 with the myocardial disease. In the 80 included patients; the mean \pm SD of the age was $49 \pm 6$ years and males were $44(55 \%)$ of the patients.

\section{Course of response}

Adequate fluid removal, as tested clinically and by ancillary methods, led to a decrease in intensity of $\mathrm{P} 2$ in all patients with a decrease in sPAP (Table 1). Prior to fluid removal; 59 patients (74\%) had grade

Table 1: Changes in the intensity of loudness of P2 and SPAP with fluid overload.

\begin{tabular}{|c|c|c|}
\hline Intensity of P2* & $\begin{array}{c}\text { Initial presentation } \\
\text { (Fluid overload) }\end{array}$ & $\begin{array}{c}\text { After adequate diuretic } \\
\text { therapy (Euovolumic state) }\end{array}$ \\
\hline 0 & 0 & $65(81 \%)$ \\
\hline 1 & 0 & $15(19 \%)$ \\
\hline 2 & $59(74 \%)$ & 0 \\
\hline 3 & $21(26 \%)$ & 0 \\
\hline $\operatorname{SPAP}^{*}(\mathrm{~mm} \mathrm{Hg})$ & $58 \pm 4$ & $28 \pm 7$ \\
\hline
\end{tabular}

P2: Second Heart Sound; sPAP: Systolic Pulmonary Arterial Pressure.

*Significant difference existed before and after fluid removal $(p<0.001)$
2 P2 and 21(26\%) grade 3 which decreased to 65(81\%) grade 0 and $15(19 \%)$ after establishment of euovolumic state $(\mathrm{P}<0.001)$. Similarly, sPAP decreased from $58 \pm 4 \mathrm{~mm} \mathrm{Hg}$ to $28 \pm 7$ after establishment of euovolumic state $(\mathrm{p}<0.001)$.

\section{Correlation between P2 and sPAP}

A significant correlation was noted between these 2 parameters ( $r s=0.94, p<0.001$ ) indicating that the grade of P2 is a useful indicator of the extent of intravascular fluid level (Figure 1).

\section{Discussion and Conclusion}

Pulmonary hypertension is caused by (a) pulmonary arterial hypertension due to systemic disorders or idiopathic defect, (b) respiratory disease and/or hypoxia such as chronic obstructive airway disease or interstitial ones, (c) thromboembolism, (d) venous hypertension due to left heart disease [9]. Moreover, patients with fluid overload have an increase in right ventricular pressure leading to an increase in pulmonary arterial pressure. In our study, and to assess the latter relation, we started by excluding patients with primary cardiac and lung diseases. Subsequently, we showed a significant drop in sPAP measurements after fluid removal which was associated with a reduction in the intensity of accentuated P2 indicating a cause-andeffect relationship since such rapid decline in sPAP cannot be seen in primary cardiac or respiratory diseases. Our finding of load P2 with fluid overload is consistent with that of Chandraratna PAN, et al., which has shown that, using high-fidelity, catheter-tipped micro-manometers and echophonocardiography, that the second sound originates from after-vibrations in the cusps and the walls and blood columns of the great vessels and their respective ventricles [10]. Hence, the loudness of each component of the second heart sound is proportional to the respective pressures in the aorta and pulmonary artery at the onset of diastole. The aortic component is normally of greater intensity than the pulmonic component. The aortic component, therefore, radiates widely over the chest, whereas the pulmonic component is heard mainly in the second left ICS with some radiation down the left sternal border. The greater radiation of the aortic component is probably due to the higher pressure in the aorta compared to that in the pulmonary artery. In our study; we excluded patients with comorbid conditions likely to alter the intensity of P2 relative to A2. They include; (a) accentuated A2 viz essential hypertension, syphilitic aortic regurgitation, hyperdynamic states (anemia, thyrotoxicosis, beriberi, and Paget's disease), (b) soft A2 viz aortic stenosis and regurgitation, (c) accentuated P2 due to primary cardiac disease viz primary pulmonary hypertension, mitral stenosis, left ventricular dysfunction, (d) soft P2 due to pulmonary stenosis, pulmonary atresia and tetralogy of Fallot [11]. Moreover, it should be noted that the intensity of P2 is normally louder in young individuals with thin chest walls due to rotation of the right ventricle assuming the position normally occupied by the left ventricle [12]. On the other side; the value of accentuated P2 may be limited in patients with emphysema and obese patients due to poor transmission of heart sound [13]. Finally, acute pulmonary embolism can produce acute accentuation of P2 with sudden shortness of breath yet an oligemic lung by simple $\mathrm{x}$-ray can assist in diagnosis.

In conclusion; clinical methods of diagnosis are essential for physicians and should be emphasized in the teaching of undergraduate medical students. Using the intensity of $\mathrm{P} 2$ provides a non-invasive, rapid and cost-effective means of assessment and follow-up of patients presenting with shortness of breath due to fluid overload.

\section{Conflict of Interests}

None. 


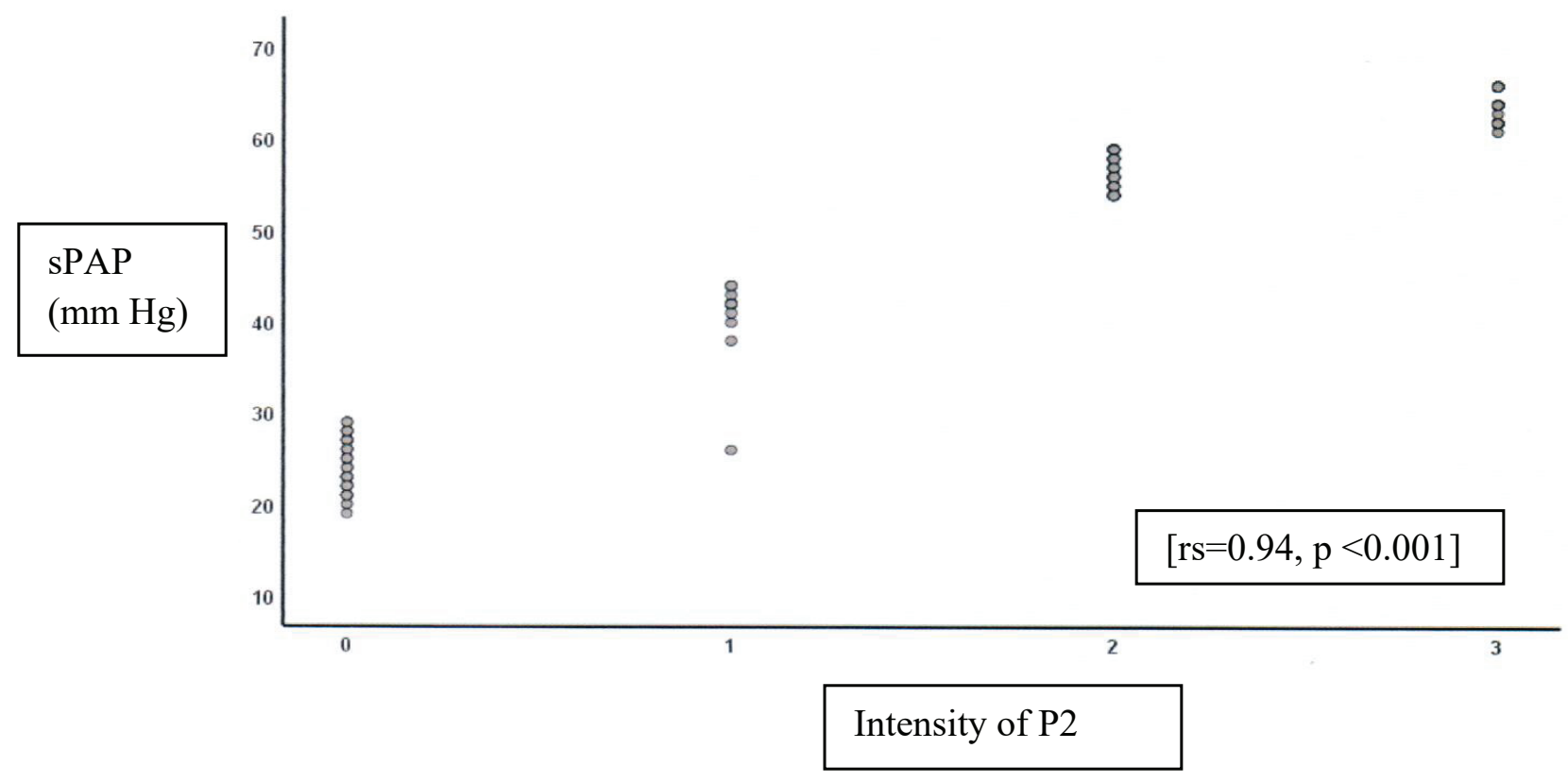

Figure 1: Correlation between intensity of second heart sound (P2) and systolic pulmonary arterial pressure (sPAP).

\section{References}

1. Claure-Del Granado R, Mehta RL (2016) Fluid overload in the ICU: evaluation and management. BMC Nephrol 17: 109.

2. Vaara ST, Korhonen AM, Kaukonen KM, Nisula S, Inkinen $\mathrm{O}$, et al. (2012) Fluid overload is associated with an increased risk for 90-day mortality in critically ill patients with renal replacement therapy: data from the prospective FINNAKI study. Crit Care 16: R197.

3. Bouchard J, Soroko SB, Chertow GM, Himmelfarb J, Ikizler TA, et al. (2009) Fluid accumulation, survival and recovery of kidney function in critically ill patients with acute kidney injury. Kidney Int 76: 422427.

4. Peacock WF, Soto KM (2010) Current techniques of fluid status assessment. Congest Heart Fail 16: S45-S51.

5. Vermeiren GL, Malbrain ML, Walpot JM (2015) Cardiac Ultrasonography in the critical care setting: a practical approach to asses cardiac function and preload for the "non-cardiologist". Anaesthesiol Intensive Ther 47: S89-S104.

6. Malbrain ML, Huygh J, Dabrowski W, De Waele JJ, Staelens A, et al. (2014) The use of bio-electrical impedance analysis (BIA) to guide fluid management, resuscitation and deresuscitation in critically ill patients: a bench-to-bedside review. Anaesthesiol Intensive Ther 46: 381-391.

7. Felker GM, Teerlink JR (2018) Diagnosis and Management of Acute Heart Failure. In: Zipes DP, Libby P, Bonow RO, Mann DL, Tomaselli GF, et al. (eds) Braunwald's Heart Disease: A Textbook of Cardiovascular Medicine. $11^{\text {th }}$ edition, Elsevier, Pennsylvania 462.

8. Cardiac Second Heart Sounds. Stanford Medicine.

9. Simonneau G, Gatzoulis MA, Adatia I, Channick RN, Celermajer D, et al. (2013) Updated clinical classification of pulmonary hypertension. J Am Coll Cardiol 62: D34-D41.
10. Chandraratna PAN, Lopez JM, Cohen LS (1975) Echocardiographic Observations on the Mechanism of Production of the Second Heart Sound. Circulation 51: 292-296.

11. Walker HK, Hurst JW, Hall WD (1990) Clinical Methods: The History, Physical, and Laboratory Examinations. $3^{\text {rd }}$ edition, Butterworths, United States.

12. Shaver JA, Salerni R, Reddy PS (1985) Normal and abnormal heart sounds in cardiac diagnosis. Part I: systolic sounds. Curr Probl Cardiol 10: 1-68.

13. Kirby B (1993) Clinical examination of the heart. Medicine International 21: 294-299. 